UNITED STATES PROGRAM FOR TECHNICAL ASSISTANCE TO IAEA SAFEGUARDS

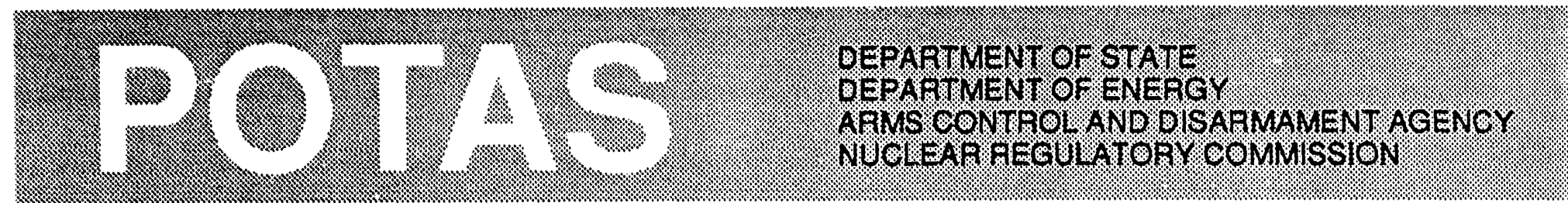

\title{
Evaluation of Bismuth Germanate Detectors
}

K. L. Swinth

P. A. Eschbach

December 1993

PACIFIC NORTHWEST LABORATORY OPERATED BY BATTELLE MEMORIAL INSTITUTE 


\title{
DISCLAIMER
}

This report was prepared as an account of work sponsored by an agency of the United States Government. Neither the United States Government nor any agency thereof, nor Battelle Memorial Institute, nor any of their employees, makes any warranty, expressed or implied, or assumes any legal liability or responsibility for the accuracy, completeness, or usefulness of any information, apparatus, product, or process disclosed, or represents that its use would not infringe privately owned rights. Reference herein to any specific commercial product, process, or service by trade name, trademark, manufacturer, or otherwise does not necessarily constitute or imply its endorsement, recommendation, or favoring by the United States Government or any agency thereof, or Battelle Memorial institute. The views and opinions of authors expressed herein do not necessarily state or reflect those of the United States Government or any agency thereof.

\author{
PACIFIC NORTHWEST LABORATORY \\ operated by \\ BATTELLE MEMORIAL INSTITUTE \\ for the \\ UNITED STATES DEPARTMENT OF ENERGY \\ under Contract DE-AC06-76RLO 1830
}

Printed in the United States of America

Available to DOE and DOE contractors from the

Office of Scientific and Technical Information, P.O. Box 62, Oak Ridge, TN 37831;

prices available from (615) 576-8401. FTS 626-8401.

Available to the public from the National Technical Information Service,

U.S. Department of Commerce, 5285 Port Royal Rd., Springfield, VA 22161. 
ISPO-359

PNL-8982

UC-606

EVALUATION OF BISMUTH GERMANATE DETECTORS
K. L. Swinth
P. A. Eschbach

December 1993

\begin{abstract}
Prepared for International Safeguards Project Office Program for Technical Assistance to the International Atomic Energy Agency the U.S. Department of Energy under Contract DE-AC06-76RLO 1830
\end{abstract}

Pacific Northwest Laboratory Richland, Washington 99352 


\section{CONTENTS}

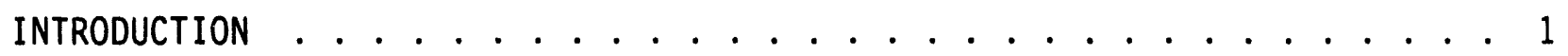

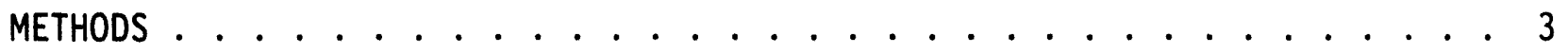

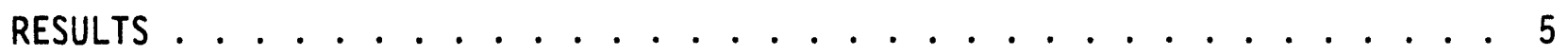

OTHER SCINTILLATORS . . . . . . . . . . . . . . . 9

DISCUSSION AND CONCLUSIONS . . . . . . . . . . . . . . 11

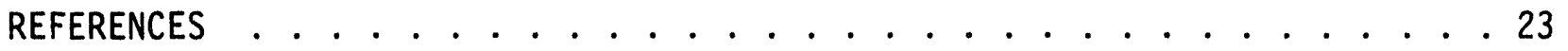

APPENDIX A - DISTRIBUTION .............. Dist-1 


\section{FIGURES}

Figure 1. Two BGO Photomultiplier Detectors . . . . . . . . . 13

Figure 2. EV Products Preamplifier and BICRON CSI Detector . . . 15

Figure 3. Spectra for Three Different Radioisotopes . . . . . . . . 17

Figure 4. BGO Detector $(0.5-\mathrm{cm}$ Thick) Spectrum for 50 Grams of Depleted $\mathrm{UO}_{2}$ Powder................ 18

Figure 5. BGO Detector (0.5-cm Thick) Spectrum for a 20-Gram Pellet of $4.3 \%$ Enriched $\mathrm{UO}_{2} \ldots \ldots . . . . .18$

Figure 6. BGO Detector (0.5- $\mathrm{cm}$ Thick) Spectrum for 2 Grams of 9.9\% Enriched $\mathrm{UO}_{2}$ Powder ........... 19

Figure 7. CsI/Photodiode Spectrum for ${ }^{137}$ Cs . . . . . . . . 19

Figure 8. Change in Peak Position Observed for a BGO Detector $\left({ }^{137} \mathrm{Cs}\right.$ Source) from $-10^{\circ} \mathrm{C}$ to $40^{\circ} \mathrm{C} \ldots 20$

Figure 9. Change in Peak Position Observed for NaI Detector $\left({ }^{13} \mathrm{Cs}\right.$ Source) from $-10^{\circ} \mathrm{C}$ to $40^{\circ} \mathrm{C} \ldots . . . .20$

\section{TABLES}

Table 1. Comparison of Scintillators in Standard Geometry . . . . 21 Table 2. Properties of Selected Scintillators . . . . . . . 22 


\section{INTRODUCTION}

During International Atomic Energy Agency (IAEA) safeguards inspections, one of the activities is the verification of materials in the inventory through quantitative or qualitative measurements. Performance of these measurements requires an array of sophisticated detectors, electronics, shields, and stands. This requires the transport and handling of delicate systems that are both heavy and bulky. The increasing sophistication and miniaturization of electronic and computer systems have led to progressive reductions in both the weight and the bulk of such electronics. However, to take full advantage of these improvements, similar reductions must also occur in the size and weight of the detectors.

The purpose of this study, performed by Pacific Northwest Laboratory $(P N L)^{(a)}$ for the IAEA, was to explore the usefulness of one type of new detector, the bismuth germanate (BGO) scintillator. This is the same detector considered in the task, "Feasibility Study on the Verification of Fresh Fuel Assemblies in Shipping Containers," ISP0-325. The purpose was to test detectors for their performance at high (fission products) and low $\left({ }^{235} \mathrm{U}\right.$ ) photon energies. Information is also provided on other scintillators, including those using photodiode-coupled cesium iodide and germanium orthosilicate.

To fully capitalize on the development of the more compact and more powerful multichannel analyzers (MCAs) and associated electronics, one must have smaller, lighter detectors to use with them. Currently, a sodium iodide detector and its associated stands, shielding, etc. are bulkier and many times heavier than the portable MCA used by the IAEA. Developments in electronics have made it possible to have an MCA that is smaller than a portable laptop computer. In fact, one available MCA is about the same size as a palmtop computer (the Scout model available from Quantrad Sensor, Santa Clara,

(a) Pacific Northwest Laboratory is operated by Battelle Memoriai Institute for the U.S. Department of Energy under Contract DEAC06-76RLO 1830. 
California), including the power source. This model actually operates with a palmtop computer. Coupled with such computers, these units can use software that in the past was limited to the laboratory system. Such small units coupled with computers provide extremely powerful data-collection and analysis capability for inspectors in the field. Although the portable MCA used by the IAEA is very effective and includes analysis programs, the programs are in firmware and must be specially developed for the system. Conceivably, a full set of hardware could be assembled including MCA, computer, power supplies, amplifiers, and detectors that would actually fit into a briefcase. However, detectors that can operate effectively with these new electronics without diminishing their size and weight advantages have yet to be developed.

In recent years, researchers have been exploring new materials for detectors (Derenzo et al. 1990; Blasse 1991). These have included scintillators that are considerably more effective at absorbing radiation than are the traditional sodium iodide (TI) models. With this capability, both the scintillator and its accompanying photomultiplier tube can be made smaller and still absorb the same fraction of incident radiation. Another advantage of a smaller detector is that the associated collimators and shields can be made smaller, thereby requiring less high-density absorbing material and thus resulting in a weight reduction. Because their small volume made them useful in areas that were not easily accessible to other detectors (Swinth and Tanner 1990), these detectors were considered for a task of the United States (U.S.) Program for Technical Assistance to IAEA Saieguards (POTAS). However, these detectors are not without their drawbacks. Although the radiation absorption is high, the conversion of absorbed energy to light is low, which reduces the resolution and the ability to detect low energies. Smaller detectors, because of their smaller areas, also lead to low efficiency in geometrical detection.

For this study, detectors were selected and evaluated experimentally in the laboratory. Other detectors are compared to the BGO, and the results and implications for safeguards measurements are discussed. 


\section{METHODS}

During the earlier study (Swinth and Tanner 1990), tests were made with a BGO crystal coupled to a standard two-inch photomultiplier. The response of the photomultiplier was not matched to the spectral output of the scintillator (BGO), and it was felt that selection of the best photomultiplier commensurate with a reduction in overall detector size was important. Although smaller photomultipliers are available, a $2.86-\mathrm{cm}$ diameter photomultiplier designed by Hamamatsu (Model R268) for use with BGO was chosen. Two detectors were purchased for evaluation: one $0.5-\mathrm{cm}$ thick for uranium analysis $(96 \%$ absorption at $186 \mathrm{keV}$ ) and one $2.54-\mathrm{cm}$ thick for higher energy photons. The detectors (both $2.86-\mathrm{cm}$ in diameter), specified in an integral assembly directly coupled to the Hamamatsu photomultiplier, included a preamplifier. A photo of the two detectors appears in Figure 1. This provided a detector package directly compatible with the Davidson 2056-4K-A MCA.

The other detectors evaluated during this study included a CSI (TI) scintillator $(1 \mathrm{~cm} \times 1 \mathrm{~cm} \times 2 \mathrm{~cm})$ coupled to a $1-\mathrm{cm} \times 2-\mathrm{cm}$ photodiode. The entire package, sealed in a light-proof box by the manufacturer, had dimensions of $4 \mathrm{~cm} \times 3 \mathrm{~cm} \times 1.5 \mathrm{~cm}$. This detector is much smaller than the commercially available preamplifiers that are used with it (Canberra 2003BT and the EV Products A1043 preamplifier). Photographs of the BGO detectors and the CSI(TI) appear in Figures 1 and 2. EV Products is now selling a CSI(Tl)/photodiode package with a built-in preamplifier; this detector has much smaller dimensions than the detector and preamplifier shown in Figure 2.

Comparisons were also made with a $7.5-\mathrm{cm}$ high $\times 7.5-\mathrm{cm}$ diameter sodium iodide detector. This was done to facilitate comparisons with other detectors since a detector of this size is used as a comparison for rating the efficiency of germanium detectors (ANSI 1986).

Pulse height distributions were collected with a Davidson MCA (model 2056-4K-A). The shaping time was set to the value for NaI; because NaI and $B G O$ have roughly the same decay constant $(0.23$ versus $0.30 \mu$ seconds, respectively), the amplifier was nearly optimal for $B G O$. However, we were not 
able to properly match the shaping time of the Davidson amplifier to the - longer decay time ( $1 \mu$ second) of the CSI(TI) scintillator. The gain on the Davidson MCA varied from 10 for the BGO detector/preamplifiers to 5000 for the CSI(TI)/photodiode combination. The area under the photopeaks was calculated using the Davidson's data-analysis functions.

To investigate the effect of temperature on the pulse height distributions from the $B G O$ detectors, they were placed in a temperature chamber. The chamber was then cooled to $-10^{\circ} \mathrm{C}$, at which point a pulse height distribution from a ${ }^{137} \mathrm{Cs}$ check source was obtained. The temperature of the chamber was elevated at the rate of $10^{\circ} \mathrm{C}$ every hour, and a new pulse-height distribution was obtained at every $10^{\circ} \mathrm{C}$ increment. 


\section{RESULTS}

Initial tests were performed with the $0.5-\mathrm{cm}$ thick and $2.5-\mathrm{cm}$ thick BGO detectors with various radioisotopes, including ${ }^{241} \mathrm{Am},{ }^{57} \mathrm{Co}$, and ${ }^{137} \mathrm{Cs}$. The spectra obtained from these test sources are plotted together in Figure 3 . As can be seen in the figure, the ${ }^{241} \mathrm{Am}$ peak (from the $60 \mathrm{-keV}$ photon) is resolved from the noise. The next two peaks are from ${ }^{57} \mathrm{Co}(122 \mathrm{keV})$ and ${ }^{137} \mathrm{Cs}$ (662 $\mathrm{keV}$ ). The positions of the peaks, which are plotted against isotope energy, were used for the energy calibration. This energy calibration was used later to aid in the analysis of the uranium photopeaks. The resolution of the $0.5-$ cm-thick BGO detector was $10.5 \%$ for ${ }^{137} \mathrm{Cs}(662 \mathrm{keV})$. Resolution at $122 \mathrm{keV}$ was approximately $33 \%$, compared with approximately $80 \%$ for the feasibility tests performed under an earlier ISPO task (Swinth and Tanner 1990). We believe that the improvernents resulted from better spectral matching of the photomultiplier and an improved light-collection geometry for the BGO crystals.

We also tested the detector's performance for the measurement of enriched uranium samples. Measurements were performed on the three bulk samples available; however, the samples were of various geometries and in different containers. Figures 4, 5, and 6 plot the data obtained with the $0.5-\mathrm{cm}$ BGO detector. The figures are arranged in ascending percent of enrichment. Figure 4 gives the pulse height distribution from the depleted uranium sample (approximately 50 grams of depleted uranium dioxide $\left[\mathrm{UO}_{2}\right]$ powder in a 2.5-cm-diameter glass jar). Figure 5 shows the pulse height distribution obtained from a $4.3 \%$ enriched uranium sample (a $20-g$ pellet in a 2.75-cm-diameter plastic jar). Figure 6 displays the pulse height distribution from a $9.9 \%$ enriched uranium sample (29 grams of $\mathrm{UO}_{2}$ powder in a 2.75-cm-diameter plastic jar). The percent enrichment of enriched samples may be calculated using a two-parameter fit:

$$
\% \text { Enrichment }=a(A 1)+b(A 2) .
$$

The two areas, $A 1$ and $A 2$, are, respectively, the region-of-interest areas for the 185-keV photopeak and an arbitrary region to the right of the $185-\mathrm{keV}$ 
photopeak. Because of the variability of the samples available, it was not feasible to test the capability of performing enrichment analysis with the BGO detectors; however, the photopeak differences for the various samples were clearly visible. The PMCA firmware package for analyzing the uranium enrichment is not available on the PNL analyzers; thus, testing for compatibility with the BGO detectors was not possible. Based on the experiments performed, we anticipate minimal changes to the firmware. This will probably involve increasing the integration region because of the poorer energy resolution of the BGO (23\% FWHM) compared to NaI (T1) (12\% FWHM).

To determine the feasibility of using a completely solid-state detector package (one with no phototube) for safeguards applications, a CsI(TI)/ photodiode detector was evaluated. Figure 7 shows the photopeak resulting from tests with a ${ }^{137} \mathrm{Cs}$ source. The resolution for the photopeak appearing in this figure is $18 \%$.

Since it is well known that scintillator-photomultiplier combinations are thermally sensitive, the performance of detectors was investigated as a function of temperature. The peak position of a ${ }^{137} \mathrm{Cs}$ photopeak versus temperature is plotted in Figure 8. The degradation of light output and/or detector response as the temperature increased was dramatic; the peak position declined by a factor of five over the temperature range from $-10^{\circ} \mathrm{C}$ to $40^{\circ} \mathrm{C}$. $\mathrm{A}$ similar experiment was conducted with a 1.25-cm-thick $\mathrm{NaI}$ detector. Figure 9 displays the data from the NaI temperature experiment. Again, the photopeak position declines with increasing temperature. But the pulse height declines by $50 \%$ over the temperature excursion of $50^{\circ}$, not by $500 \%$ as occurred with the $B G O$ detector. The $0.5-\mathrm{cm}$-thick BGO detector has approximately the same absorption as does the $1.25-\mathrm{cm} \mathrm{NaI}$ detector.

Following recommendations in ANSI/IEEE Standard 325 - 1986, "IEEE Standard Test Procedures for Germanium Detectors" (ANSI 1986), we adopted the relative full-energy method for peak-counting efficiency to test the scintillators. This technique was used to facilitatc comparisons with other detectors. 
The technique requires counting a ${ }^{60} \mathrm{Co}$ source at $25 \mathrm{~cm}$ distance and analyzing the $1332.5-\mathrm{keV}$ photopeak intensity for comparison of the $\mathrm{BGO}^{\prime} \mathrm{s}$ efficiency with that of a $3-i n . \times 3-i n .(7.6-\mathrm{cm} \times 7.6-\mathrm{cm})$ sodium iodide detector. In tests with a ${ }^{60}$ Co source, the photopeaks (1332 and $1172 \mathrm{keV}$ ) were not adequately resolved, and a ${ }^{137} \mathrm{Cs}$ source was substituted. A $6.85-\mu \mathrm{Ci}$ ${ }^{137} \mathrm{Cs}$ source was placed at $25 \mathrm{~cm}$ from the detectors and counted until sufficient counts were accumulated to minimize statistical error. Table 1 summarizes the data. Under this test, the $7.6-\mathrm{cm} \times 7.6-\mathrm{cm}$ sodium iodide detector is clearly superior to the BGO in terms of efficiency. Correcting the BGO counts for absorption and detector area makes them comparable to the 7.6$\mathrm{cm} \times 7.6-\mathrm{cm}$ detector within the expected errors in thickness and diameter of the nominal detector dimensions. The efficiency of the cesium iodide detector is much lower than one would predict. The reason for the lower efficiency is unknown. However, it is important to consider the detector area when selecting a detector. The sodium iodide and $B G O(2.5-\mathrm{cm})$ detectors have comparable absorption efficiencies at $662 \mathrm{keV}$, but because of its lower geometrical efficiencies, the $B G O$ detector will take 8.5 times as long to accumulate the same net counts as the $\mathrm{NaI}(\mathrm{TI})$ detector. 


\section{OTHER SCINTILLATORS}

In recent years, there has been renewed interest in scintillators for a variety of applications. Much of the recent research on scintillators has been driven by their use in medical scanners that use hundreds of scintillator-photomultiplier detectors for the production of tomographic images. The resolution of the systems is dictated by the size of the scintillator (imaging element) while the efficiency is dictated by the absorption of the radiation. Thus, the requirements for this application are similar to our needs: high efficiency and small volume. An important difference for our application is the need for separation of photopeaks and a good photopeak-to-Compton ratio. This translates to a high efficiency in the conversion of incident gamma rays into optical energy (photons).

Currently, scientists are searching for likely candidates for scintillator materials (Derenzo et al. 1990). This search has turned up some interesting cardidate materials, such as lead tungstate. Unfortunately, lead tungstate has a low conversion efficiency, only $4.4 \%$ of that of BGO (Kobayashi et al. 1993). It is clear from Table 2, which displays data for several scintillators, that an improvement in the conversion efficiency of BGO would be beneficial.

Rather than achieving reduced scintillator size by choosing one with high radiation-ausorbing properties, in some cases (such as with CsI[TI] scintillators), the photomultiplier itself could be replaced by a silicon photodiode. The best technology in photomultipliers is captured in tubes typically in the range of one-to-two inches in diameter; this leads to a bulky detector system regardless of scintillator size. Increasing the volume of the scintillator and compensating with a smaller photodiode is an attractive al ternative. CSI(TI) crystals up to $3 \mathrm{~kg}$ have been coupled to photodiodes (Kotthaus 1993) for use as radiation detectors. Unfortunately for large detectors, there are several competing factors that must be considered. The area of the crystal covered by the photodiode (aperture) needs to be maximized to improve light-collection efficiency and thus resolution. This leads to larger photodiodes, that are noisier due to their larger capacitance, which in 
turn results in poorer resolution. One promising avenue in this regard is the development of the drift silicon diodes (Avset et al 1989), which will have negligible capacitance regardless of size. Unfortunately, although work has been going on in this area for several years, progress has been extremely slow.

Another approach to the problem would be to use a photodiode with the BGO scintillator. As noted in Table 2, however, using a photodiode results in a loss in resolution, particularly for $B G O$. This is due to the poor match of the scintillation wavelength of the $B G O$ to the spectral sensitivity of the diode. There have been proposals to use dopants to shift the spectral output of the BGO, but there does not appear to be any active work in this area.

The recently developed gadolinium orthosilicate (GSO) scintillator shows considerable potential because of its sensitivity to thermal neutrons (Reeder 1992; Melcher et al. 1990). Due to the high cross-section of gadolinium, only very thin scintillators $(11 \mu \mathrm{m})$ are required for $100 \%$ efficiency in capturing incident thermal neutrons. However, the scintillator must be thick enough to capture the major neutron signature peaks at approximately $33 \mathrm{keV}$ and $77 \mathrm{keV}$. Such a scintillator could be used for both neutron and photon counting in safeguards applications. Unfortunately, the low energy of the photopeaks makes them susceptible to interference from higher-energy photons, and the 77 keV peak can suffer interference from lead $X$-rays produced in shielding. This problem could be mitigated by a number of means, such as phoswich detectors and coincidence schemes, but these would add to the complexity of the detector system. Currently, possibilities in this area are not being pursued. 


\section{DISCUSSION AND CONCLUSIONS}

We tested a number of BGO detectors and one CSI scintillator coupled to a photodiode. The detectors proved to have inadequate resolution for many applications. However, they do function acceptably when compact detectors are needed for the analysis of uranium enrichment or for the gross identification of fission product photons. Temperature tests were also performed on the detectors, and their responses all show a strong dependence on temperature. For the $B G O$ detectors, the coefficient is $-1.6 \% /{ }^{\circ} \mathrm{C}$; for the NaI detectors, it is $-0.8 \% /{ }^{\circ} \mathrm{C}$.

In many cases, the resolution quoted in the literature for similar detectors is better than that observed in our tests; in some cases it is not as good. Differences in optical coupling, spectral sensitivity, detector dimensions, etc. can influence these parameters.

Our results cleariy show that the BGO detector can replace the $\mathrm{NaI}$ detector for uranium enrichment analysis and for counting of uranium in fuel assemblies. However, one must note that the reduction in diameter from $5.0 \mathrm{~cm}$ to $2.8 \mathrm{~cm}$ will result in a decrease in geometrical efficiency of approximately $70 \%$ if compared to a $5-\mathrm{cm} \times 5-\mathrm{cm}$ sodium iodide detector.

Scintillation detectors will never compete with solid-state detectors in terms of resolution. Thus, inspectors will be forced to continue to rely upon high-resolution detectors for most plutonium analysis. 


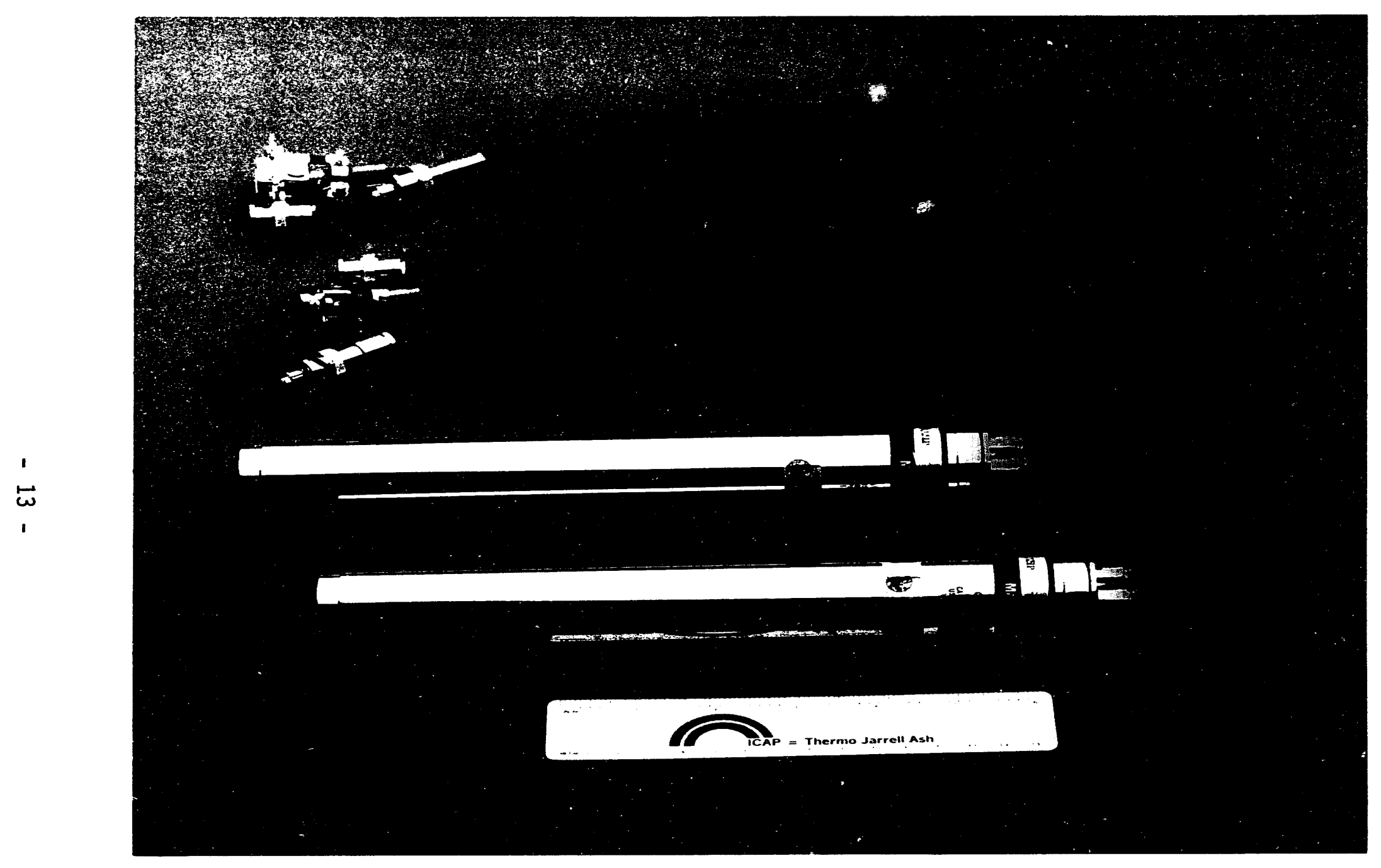

Figure 1. Two BGO Photomultiplier Detectors (15-cm ruler is shown for scale.) 


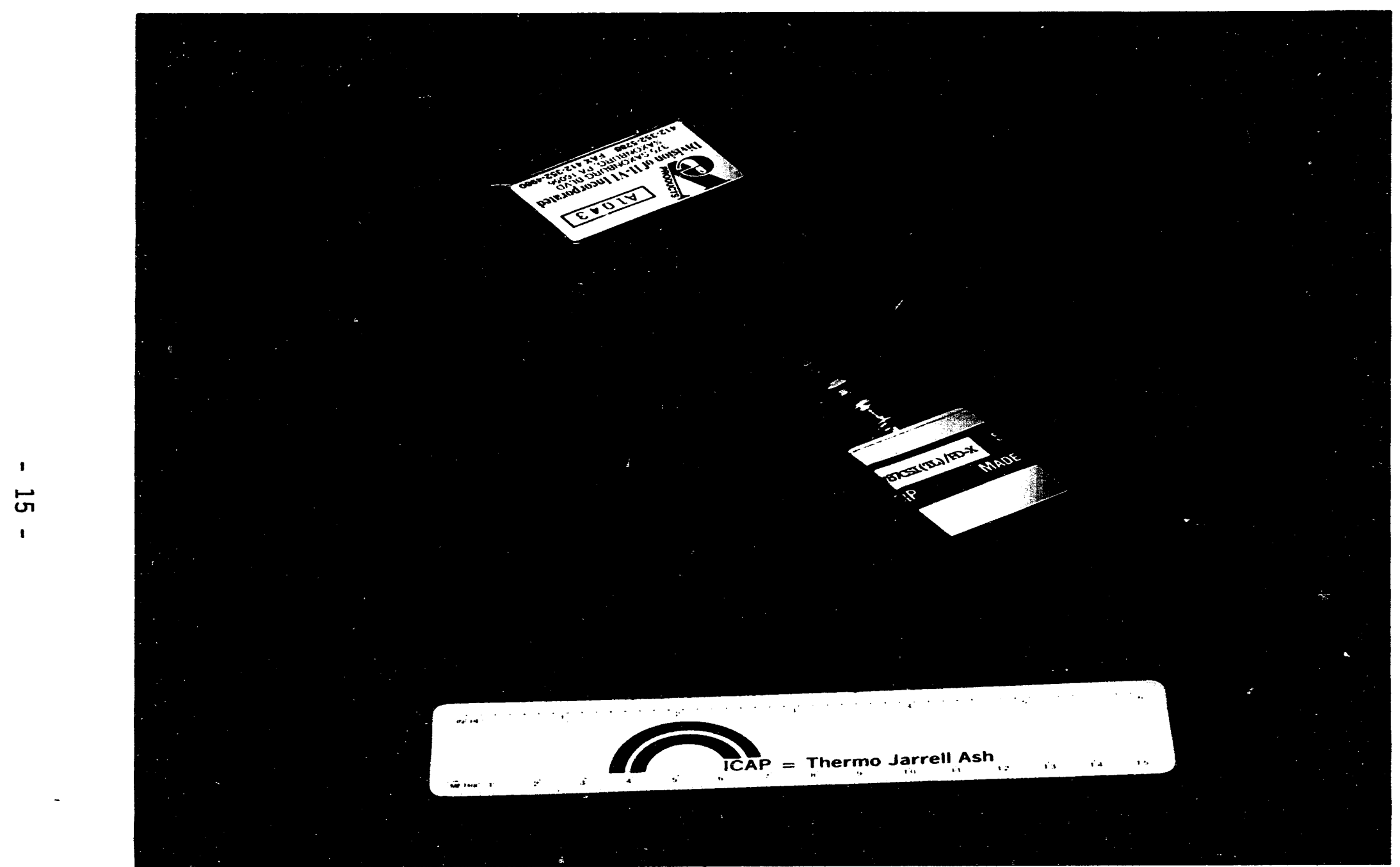

Figure 2. EV Products Preamplifier and BICRON CSI Detector (15-cm ruler is shown for scale.) 


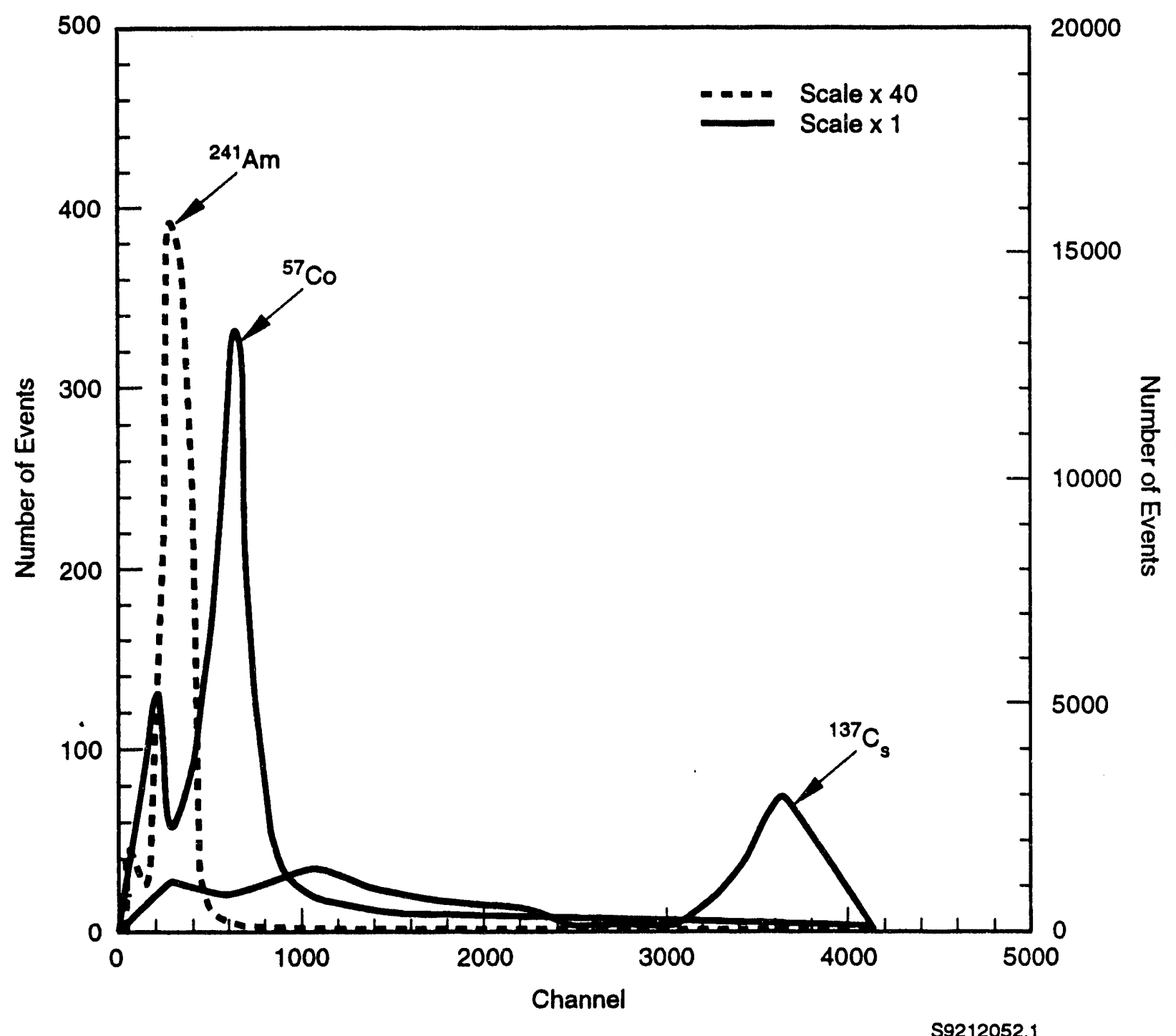

Figure 3. Spectra for Three Different Radioisotopes (Due to the higher activity of the americium source, the scale was reduced by a factor of 40 when overlaying the americium photopeak.) 


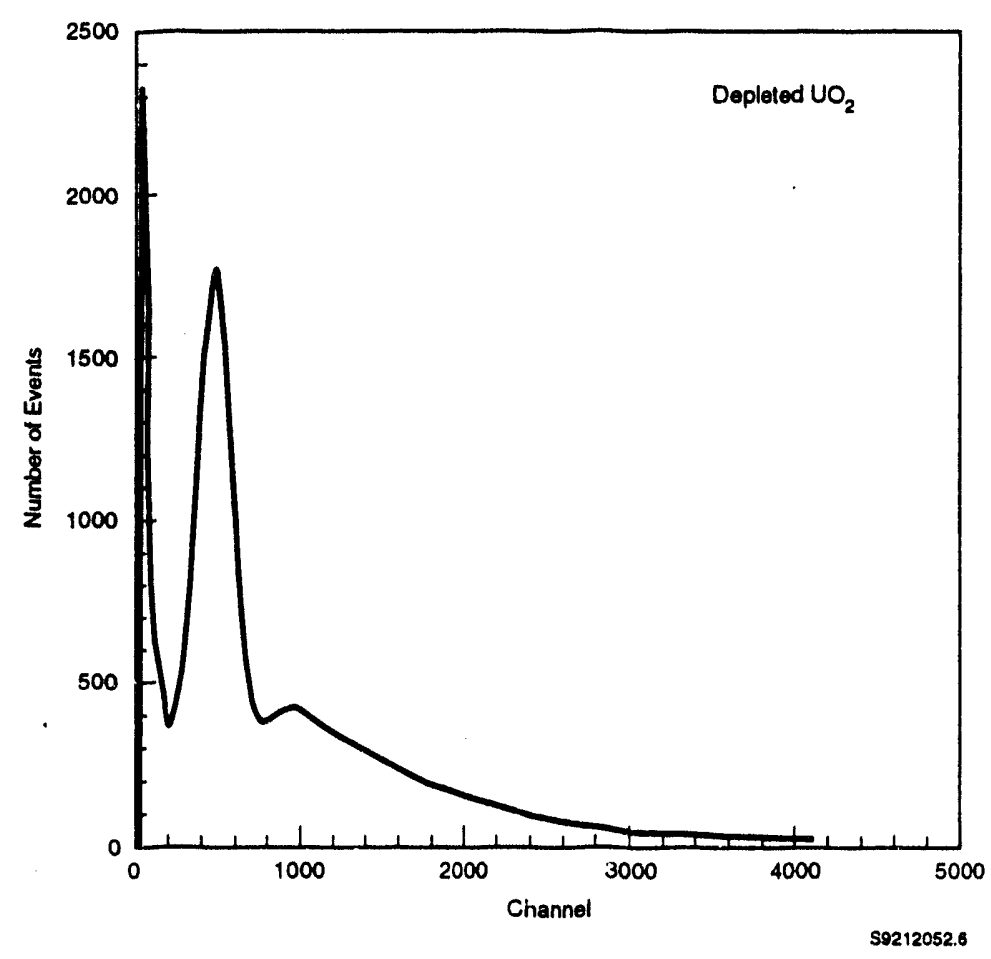

Figure 4. BGO Detector (0.5- cm Thick) Spectrum for 50 Grams of Depleted $\mathrm{UO}_{2}$ Powder

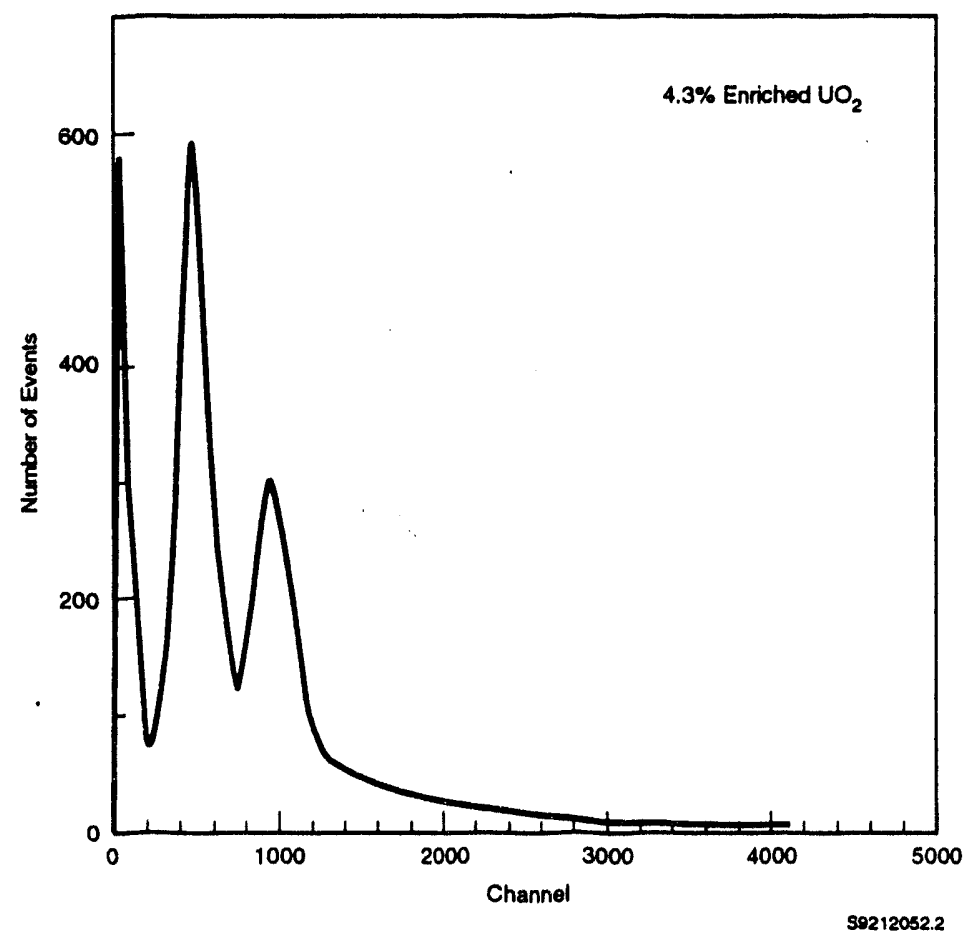

Figure 5. BGO Detector $(0.5-\mathrm{cm}$ Thick) Spectrum for a 20-Gram Pellet of $4.3 \%$ Enriched $\mathrm{UO}_{2}$ 


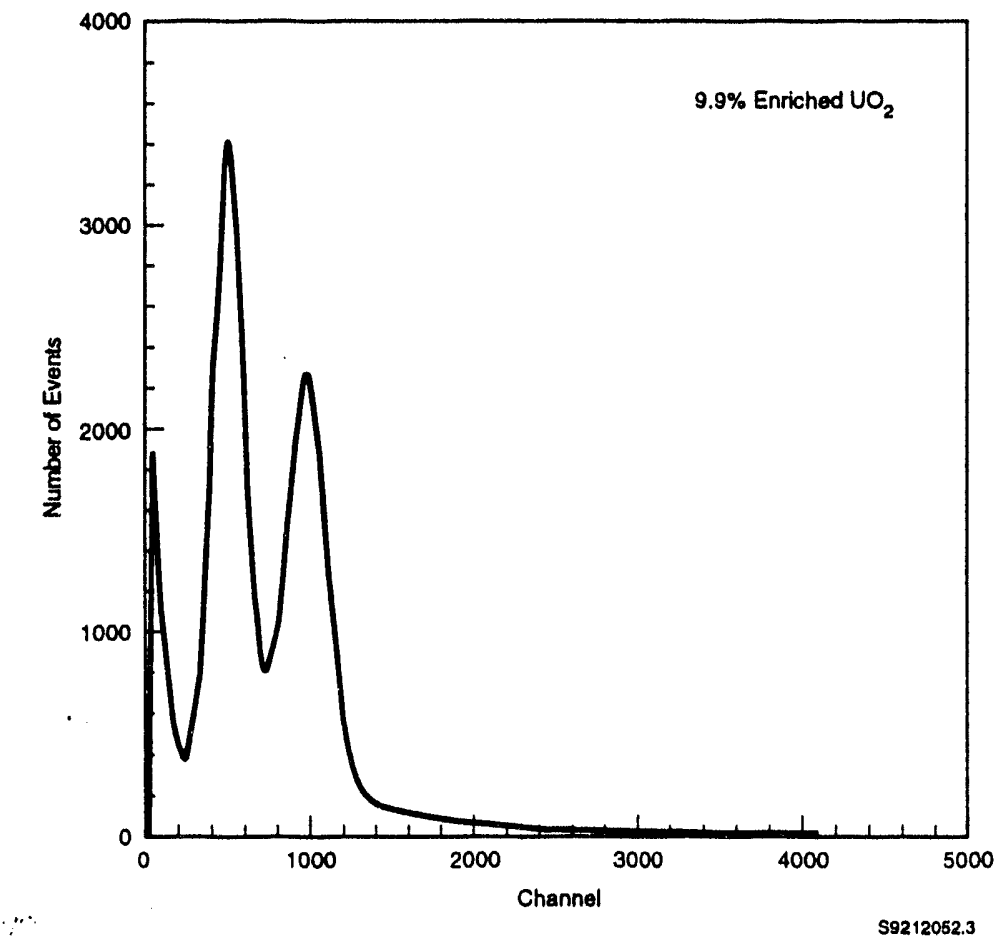

Figure 6. BGO Detector $(0.5-\mathrm{cm}$ Thick) Spectrum for 2 Grams of 9.9\% Enriched $\mathrm{UO}_{2}$ Powder

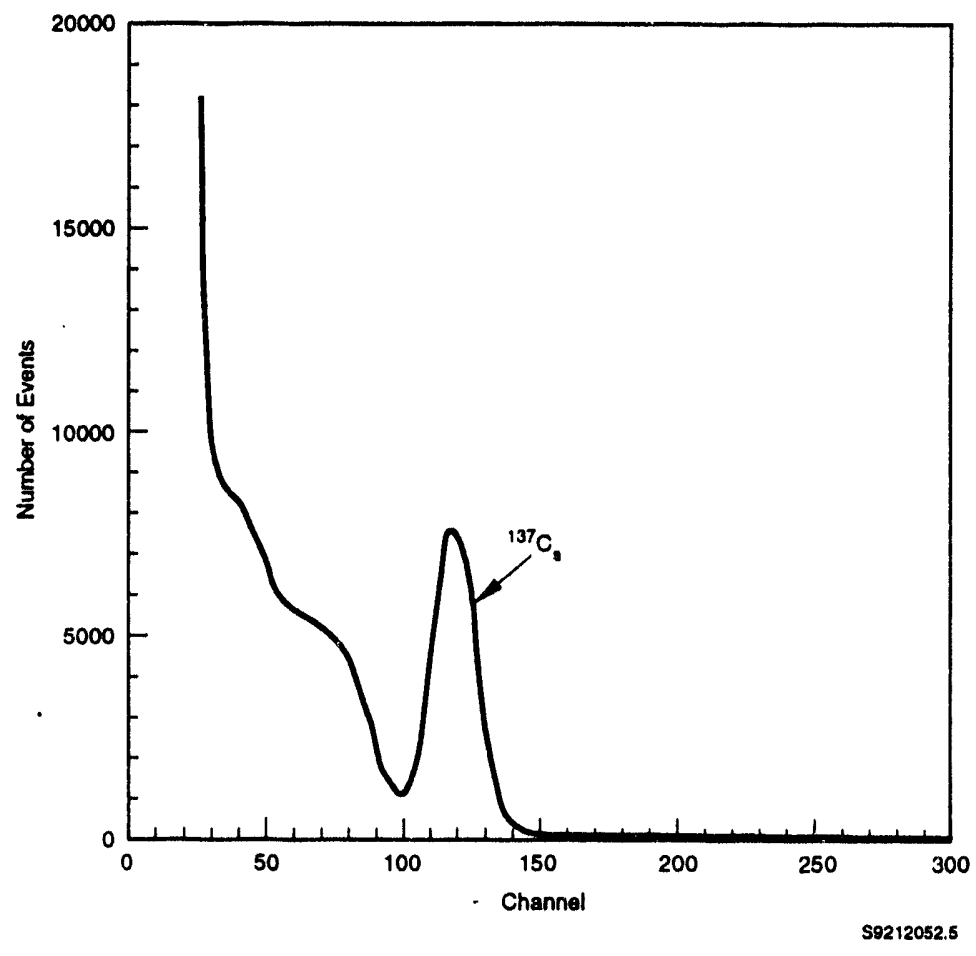

Figure 7. CsI/Fhotodiode Spectrum for ${ }^{137}$ Cs 


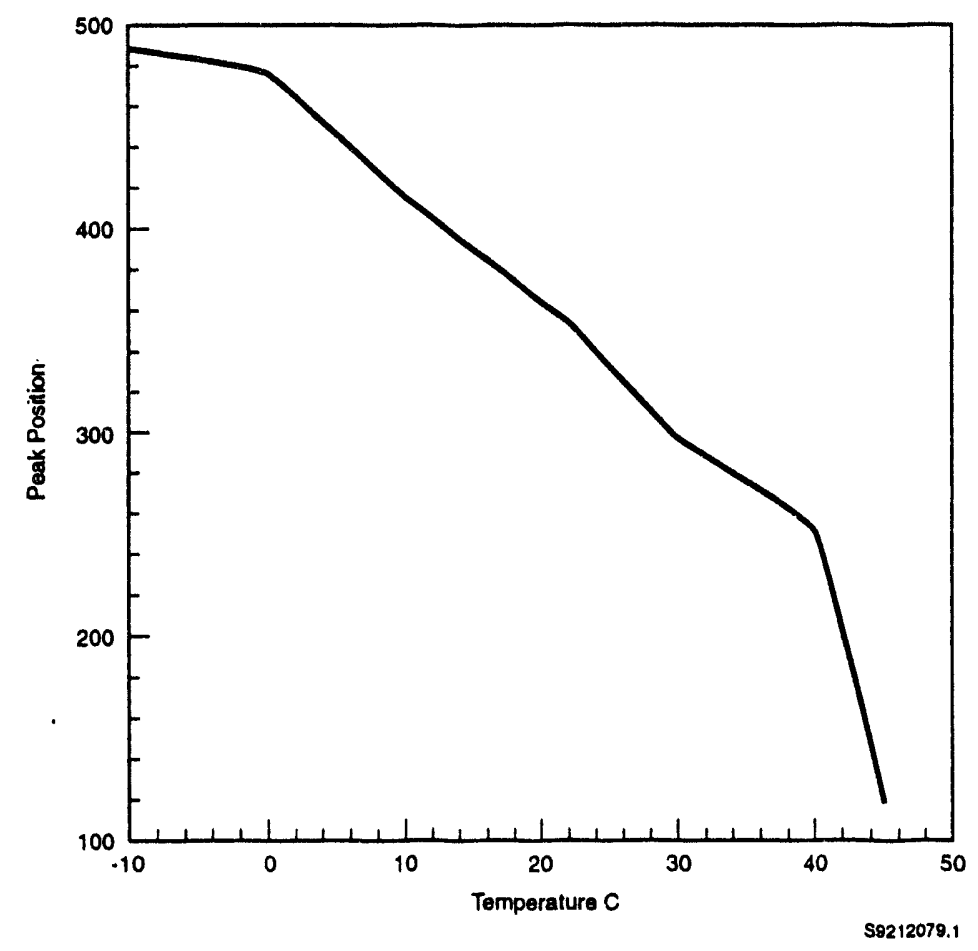

Figure 8. Change in Peak Position Observed for a BGO Detector $\left({ }^{137}\right.$ Cs Source) from $-10^{\circ} \mathrm{C}$ to $40^{\circ} \mathrm{C}$

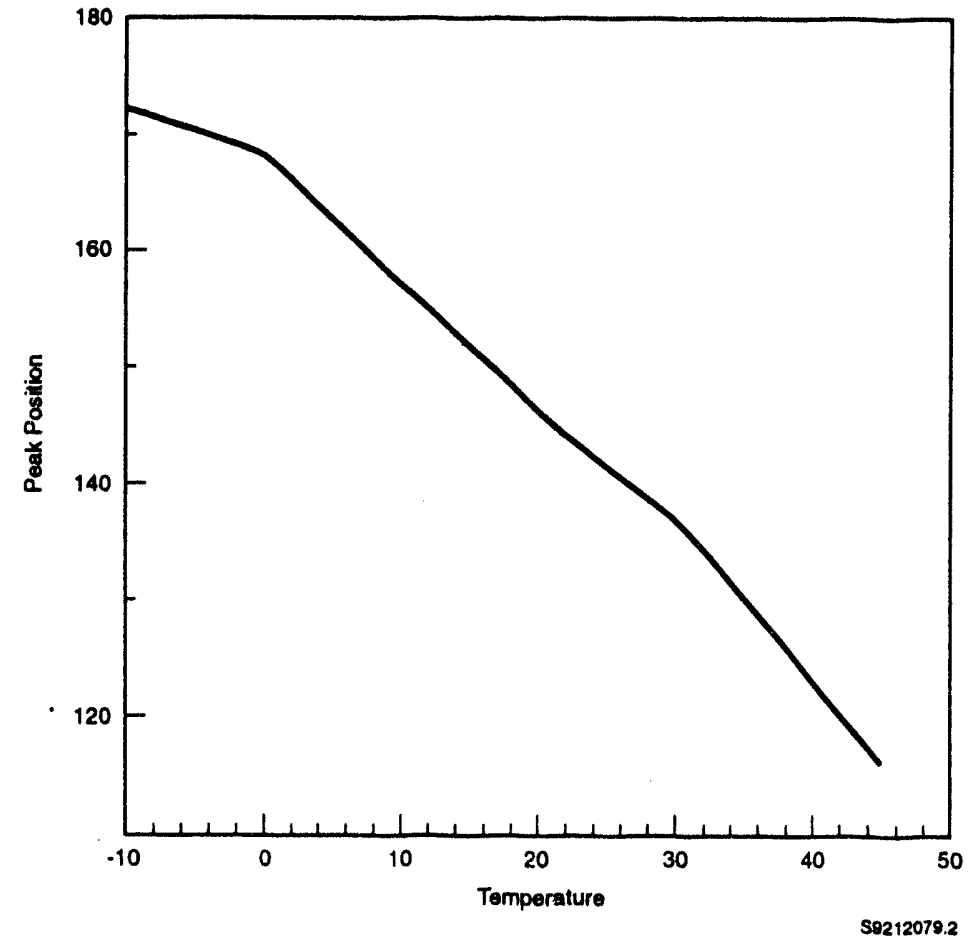

Figure 9. Change in Peak Position Observed for NaI Detector $\left({ }^{137} \mathrm{Cs}\right.$ Source) from $-10^{\circ} \mathrm{C}$ to $40^{\circ} \mathrm{C}$ 
Table 1. Comparison of Scintillators in Standard Geometry

\begin{tabular}{||l|c|c|c|c||}
\hline \multicolumn{1}{|c|}{ Scintillator } & $\begin{array}{c}\text { Dimensions (a) } \\
(\mathbf{c m})\end{array}$ & $\begin{array}{c}\text { Absorptjign at 662 } \\
\mathbf{k e V}(\mathbf{c})\end{array}$ & $\begin{array}{c}\text { Area } \\
(\mathbf{(})\end{array}$ & $\begin{array}{c}\text { Net Photopeak } \\
\text { Counts }\end{array}$ \\
\hline Sodium Iodide & $7.6 \times 7.6$ & $90 \%$ & 45.60 & 298,000 \\
\hline BGO & $2.5 \times 2.8$ & $81 \%$ & 6.16 & 33,500 \\
\hline BGO & $0.5 \times 2.8$ & $28 \%$ & 6.16 & 13,860 \\
\hline Cesium Iodide & $1 \times 1 \times 2^{(b)}$ & $34 \%$ & 2.00 & 1,710 \\
\hline
\end{tabular}
(a) Height $x$ diameter
(b) Thickness $x$ width $x$ length
(c) Calculated 
Table 2. Properties of Selected Scintillators

\begin{tabular}{|c|c|c|c|c|c|}
\hline \multirow[t]{2}{*}{ Material } & \multirow{2}{*}{$\begin{array}{l}\text { Relasive } \\
\text { Light Yield }\end{array}$} & \multicolumn{2}{|c|}{$\begin{array}{l}\text { 99\% Absorption Length } \\
(\mathrm{mm})\end{array}$} & \multirow{2}{*}{$\begin{array}{c}\text { Energy } \\
\text { Resolution at } \\
662 \mathrm{keV}(\%)\end{array}$} & \multirow{2}{*}{$\begin{array}{l}\text { Principal } \\
\text { Decay Jjme } \\
\text { (ns) }(c)\end{array}$} \\
\hline & & $186 \mathrm{keV}$ & $662 \mathrm{keV}$ & & \\
\hline $\begin{array}{l}\text { Bismuth Germanate } \\
\text { (BG0) }\end{array}$ & $1.0^{(\mathrm{a})}$ & 7.2 & 70.8 & $9.05(40.8)^{(e)}$ & 390 \\
\hline $\begin{array}{l}\text { Gadolinium } \\
\text { Oxysilicate (GSO) }\end{array}$ & $1.4^{(a)}$ & -- & -- & $7.8^{(f)}$ & 43 \\
\hline $\begin{array}{l}\text { Yttrium Aluminum } \\
\text { Oxide }\end{array}$ & $2.4^{(a)}$ & -- & -- & -- & 31 \\
\hline $\begin{array}{l}\text { Cesium Iodide } \\
(\mathrm{CsI}: T 1)\end{array}$ & $\begin{array}{c}6.2^{(b)} \\
(5.3)^{(c)}\end{array}$ & 20.0 & 110 & $5.66(7.64)^{(e)}$ & $1000^{(d)}$ \\
\hline $\begin{array}{l}\text { Sodium Iodide } \\
\text { (NaI:Tl) }\end{array}$ & $\begin{array}{c}4.8^{(b)} \\
(4.3)^{(c)}\end{array}$ & 31.8 & 154 & 7.07 & $230^{(d)}$ \\
\hline $\begin{array}{l}\text { Barium Fluoride } \\
\left(\mathrm{BaF}_{2}\right)\end{array}$ & $\begin{array}{c}-1.0^{(b)} \\
(1.05)^{(c)}\end{array}$ & 20.0 & 135 & 11.4 & $630^{(d)}$ \\
\hline
\end{tabular}
(a) Ziegler et a1. (1993)
(b) Holl, Lorenze, and Mageras (1988)
(c) Sakai (1987)
(d) Harshaw/Filtrol Scintillation Phosphor Catalog
(e) Resolution with silicon diode (Sakai 1987); others with photomultiplier tube
(f) Melcher et al. (1990) 


\section{REFERENCES}

American National Standards Institute (ANSI). 1986. "IEEE Standard Test Procedures for Germanium Gamma-Ray Detectors." ANSI/IEEE Standard 325-1986. American National Standards Institute, New York, New York.

Avset, B. S., J. A. Ellison, L. Evensen, G. Hall, T. E. Hansen, S. Roe, and R. Wheaton. 1989. "A Silicon Drift Photodiode." IEEE Trans. Nuc. Sci. 36, pp. 295-299.

Blasse, G. 1991. "Search for New Inorganic Scintillators." IEEE Trans. Nuc. Sci. 38, pp. 30-31.

Derenzo, S. E., W. W. Moses, J. L. Cahoom, R. C. C. Perera, and J. E. Litton. 1990. "Prospects for New Inorganic Scintillators." IEEE Trans. Nuc. Sci. 37, pp. 203-208.

Ho11, I., E. Lorenze, and G. Mageras. 1988. "A Measurement of the Light Yield of Common Inorganic Scintillators." IEEE Trans. NUC. Sci. 35, pp. 105109.

Kobayashi, M., M. Ishii, Y. Usuki, and H. Yahagi. 1993. "Scintillation Characteristics of $\mathrm{PbWO}_{4}$ Single Crystals at Room Temperature." Nuc. Instr. and Meth. A333, pp. 429-433.

Kotthaus, R. 1993. "CSI(TI) - Photodiode Detectors for Spectroscopy at Low Radiation Levels." Nuc. Instr. and Meth. A329, pp. 433-439.

Melcher, C. L., J. S. Schweitzer, T. Utsu, and S. Akiyama. 1990.

"Scintillation Properties of GSO." IEEE Trans. Nuc. Sci. 37, pp. 161-164.

Reeder, P. L. 1992. "Detection of Thermal Neutrons With GSO Scintillator." PNL-SA-21840, Pacific Northwest Laboratory, Richland, Washington.

Sakai, E. 1987. "Recent Measurements on Scintillator-Photodetector Systems." IEEE Trans. Nuc. Sci. NS-34, pp. 418-422.

Swinth, K. L., and J. E. Tanner. 1990. "Feasibility Study on the Verification of Fresh Fuel Assemblies in Shipping Containers." PNL-7466, Pacific Northwest Laboratory, Richland, Washington.

Ziegler, S. I., J. G. Rogers, V. Selivanov, and I. Sinitzin. 1993.

"Characteristics of the New $\mathrm{YAlO}_{3}$ : Ce Compared with $\mathrm{BGO}$ and GSO." IEEE Trans. Nuc. Sci. 40, p. 194. 
ISPO-359

PNL-8982

UC-606

\section{DISTRIBUTION}

No. of

Copies

K. E. Sanders

Safeguards and Security

Department of Energy

Washington, D.C. 20545

12 DOE Office of Scientific and Technical Information

3 R. Arlt

International Atomic Energy Agency

Wagramerstrasse 5

P.0. Box 100

A-1400 Vienna, Austria
No. of

Copies

75 J. Skalyo

International Safeguards Project Office

Building 197

Upton, NY 11973

ONSITE

DOE Richland Operations office

A. C. Walker

15 Pacific Northwest Laboratory

O. P. Amacker, Jr.

J. B. Brown

P. A. Eschbach

K. L. Soldat

K. L. Swinth (5)

Publishing Coordination Technical Report Files

Dist-1 

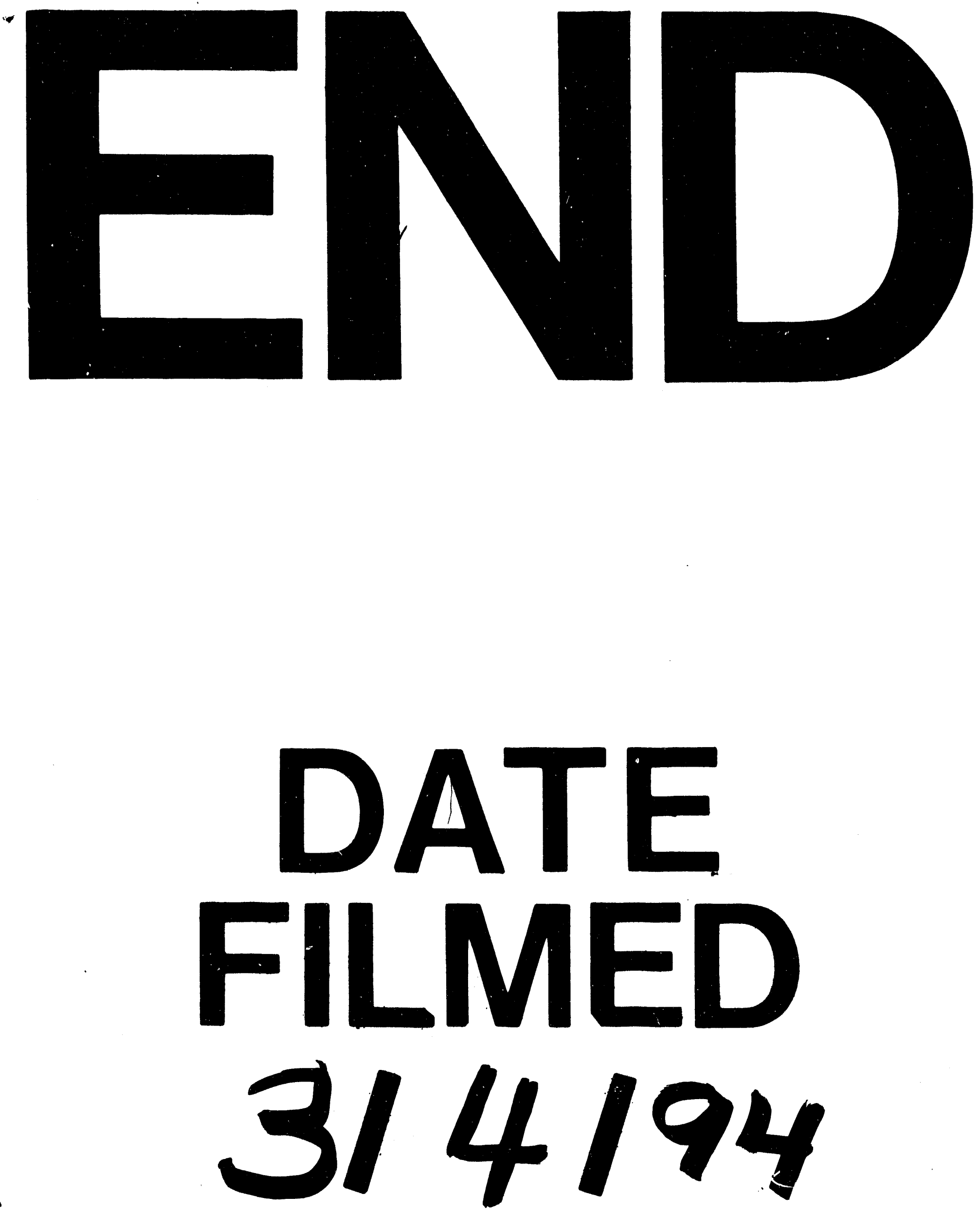